\title{
CLASSIFICAÇÃO DO TOMATE DE MESA CULTIVADO NOS SISTEMAS CONVENCIONAL E ORGÂNICO'
}

\author{
Sila Mary Rodrigues FERREIRA , Diomar Augusto de QUADROS ${ }^{3}$, Renato João Sossela de FREITAS
}

\section{RESUMO}

O trabalho teve como objetivo realizar a classificação dos tomates de mesa (Licopersicon esculentum Mill.) convencional e orgânico comercializados na Região Metropolitana de Curitiba. Foram avaliadas seis amostras de tomates do sistema convencional e três de tomates do sistema orgânico. Os frutos foram classificados em: grupos, oblongo e redondo; subgrupos: verde maduro, pintado, rosado, vermelho e vermelho maduro e classes: gigante, grande, médio e pequeno. De acordo com a ocorrência de defeitos graves e leves nos frutos, os tomates foram classificados também em tipos: extra, especial ou selecionado e comercial. As amostras cultivadas no sistema convencional foram classificadas como do grupo redondo e plurilocular, enquanto que as do sistema orgânico do grupo oblongo e bilocular. Na classe houve um predomínio de frutos médios e nos subgrupos de frutos rosado e vermelho. Em relação ao tipo, todas as amostras foram classificadas como fora do padrão ou do tipo.

Palavras-chave: Lycopersicon esculentum; classificação comercial; sistema de cultivo.

\section{SUMMARY}

CLASSIFICATION OF THE TOMATO CULTIVATED IN THE ORGANIC AND CONVENTIONAL CROPPING SYSTEMS. The objective of this work was the classification of the tomato (Lycopersicon esculentum Mill.) cultivated in the organic and conventional cropping systems and commercialized in the Metropolitan Area of Curitiba. Six samples of conventionally grown tomatoes and three samples of organic tomatoes were evaluated. The fruits were classified in groups (oblong and round), subgroups (mature green, breaker, pink, red and mature red), and classes (giant, big, medium and small). According to the occurrence of serious damage and small defects on the fruits, they were classified in types, which can be extra, special or selected and commercial. The samples of conventional systems were classified as round and with than two locules, while of organic systems was classified as oblong and with two locules. Concerning the classes, the medium fruits predominated in the pink and red subgroups. All the samples were classified as out of standard or type due to the occurrence of defects.

Keywords: Lycopersicon esculentum; commercial classification; cropping systems.

\section{1 - INTRODUÇÃO}

A classificação, além de auxiliar na comercialização, desempenha um papel econômico significativo [18] para o comprador e vendedor, tanto no comércio externo como interno. Para MORAIS [21] e ANDREUCCETTI et al. [2], um grande número de produtores vem aderindo à classificação de produtos como forma de melhorar a comercialização e o preço $[3,18]$. Além de agregar valor, através da classificação, o cliente paga o preço equivalente ao tipo do produto que está adquirindo. Em contraponto, é preciso que a legislação esteja em consonância com a realidade dos produtores. No caso do tomate convencional, a atual legislação de classificação [6] não leva em consideração as diferenças regionais, condições climáticas, de solo e manejo, o que dificulta a comercialização de produtos não enquadrados com a legislação vigente. Em muitos casos, é mais econômico ao produtor deixar o tomate deteriorar-se no solo ou transformá-lo, em vez de comercializá-lo in natura pois, fora do padrão, principalmente

Recebido para publicação em 06/04/2005. Aceito para publicação em 31/08/2005 (001506). Extraído da Tese de Doutorado do primeiro autor.

Departamento de Nutrição, Universidade Federal do Paraná. Endereço: Av. Lothário Meissner, 3400, Campus III, Jardim Botânico. CEP: 80210-170, Curitiba-PR.E-mail: sila@milenio.com.nr

Programa de Pós-Graduação em Tecnologia de Alimentos, Universidade Federal do Paraná.

"Programa de Nutrição, Faculdades Integras "Espírita".

A quem a correspondência deve ser enviada. em relação ao tamanho, o produto perde o seu valor comercial. De outro lado, estão os percentuais dos defeitos que definem o tipo do produto, sendo também fatores limitantes da sua classificação. Pergunta-se: "Será que ao aplicar a legislação (classificação), os produtos comercializados são equivalentes ao tipo do produto? Ou será que nossos produtores não estão preparados para adotála?"

Contudo, o tomate orgânico não dispõe de legislação para padrão de identidade e qualidade e, apesar de estar sendo proposto na Portaria SARC/MAPA nº 085 do Anexo XVII [7], na classificação do tomate de mesa, o anteprojeto não levou em conta as diferenças individuais dos sistemas produtivos (orgânico e convencional). "Então ao adotar essa legislação, qual o comportamento dos produtos do sistema orgânico em relação à classificação? Serão subjugados em razão das diferenças ou não?"

Dada as escassas informações técnico-científicas sobre classificação de tomates cultivados nos sistemas convencional e orgânico, o presente trabalho teve como objetivo classificar o tomate de mesa (Licopersicon esculentum Mill.) cultivado nos sistemas convencional e orgânico comercializado na Região Metropolitana de Curitiba (RMC), no período de fevereiro de 2000 a janeiro de 2002.

\section{2 - MATERIAL E MÉTODOS}

\section{1 - Matéria-prima}

Foram avaliadas seis amostras de tomate de mesa cultivado no sistema convencional (SC) e três de tomate 
TABELA 1 - Tomate de mesa cultivado nos sistemas convencional e orgânico comercializado na RMC no período de fevereiro de 2000 a janeiro de 2002

\begin{tabular}{|c|c|c|c|c|c|c|c|}
\hline AMOSTRA & SISTEMA & GRUPO & CULTIVAR & $\begin{array}{l}\text { NÚMERO DE } \\
\text { LÓCULOS }\end{array}$ & PROCEDENCIA & DATA & $\begin{array}{l}\text { TEMPERATURA } \\
\text { MÉDIA }\left({ }^{\circ} \mathrm{C}\right)\end{array}$ \\
\hline $\mathrm{SC1}$ & Convencional & Oblongo, Santa Cruz & cv. Santa Clara & Trilocular & CEASA $1 /$ PR & Fevereiro de 2000 & $26 \pm 2$ \\
\hline $\mathrm{SC} 2$ & Convencional & Redondo, Salada & cv. Raisa (LV) & Plurilocular & $\mathrm{CEASA}^{1} / \mathrm{PR}$ & Fevereiro de 2000 & $18 \pm 2$ \\
\hline $\mathrm{SC} 3$ & Convencional & Redondo, Salada & cv. Raisa (LV) ${ }^{2}$ & Plurilocular & Colombo/PR & Dezembro de 2001 & $26 \pm 2$ \\
\hline $\mathrm{SC} 4$ & Convencional & Redondo, Salada & cv. Raísa (LV) ${ }^{3}$ & Plurilocular & Colombo/PR & Janeiro de 2002 & $25 \pm 2$ \\
\hline SC5 & Convencional & Oblongo, Santa Cruz & cv. Santa Clara & Trilocular & Sabina/SP & Setembro de 2000 & $13 \pm 2$ \\
\hline SC6 & Convencional & Redondo, Salada & cv. Carmen (LV) & Plurilocular & Mogiguaçu/SP & Setembro de 2000 & $13 \pm 2$ \\
\hline $\mathrm{SO} 1$ & Orgânico & Oblongo, Santa Cruz & cv. Santa Clara ${ }^{3}$ & Bilocular & Campo Magro/PR & Fevereiro de 2001 & $26 \pm 2$ \\
\hline $\mathrm{SO} 2$ & Orgânico & Oblongo, Santa Cruz & cv. Santa Clara ${ }^{2}$ & Bilocular & Campo Largo/PR & Dezembro de 2001 & $27 \pm 2$ \\
\hline SO3 & Orgânico & Oblongo Santa Cruz & cv. Santa Clara ${ }^{3}$ & Bilocular & Campo Largo/PR & Janeiro de 2002 & $28 \pm 2$ \\
\hline
\end{tabular}

de mesa cultivado no sistema orgânico (SO), comercializado no periodo de fevereiro de 2000 a janeiro de 2002 pela Associação d'Agricultura Orgânica do Paraná - AOPA, Associação de Produtores Agrícolas de Colombo - APAC, Central de Abastecimento do Paraná - CEASA e uma loja da rede de hipermercados da RMC, conforme descrição do Tabela 1.

\section{2 - Delineamento experimental}

Na coleta de amostras de diferentes locais, foram retiradas aleatoriamente quatro caixas e conduzidas para o laboratório. Foram homogeneizadas em cubas de aço inoxidável e retiradas em profundidades diferentes de nove pontos (laterais, superiores, inferiores e intermediário) até atingir a quantidade desejada. A seguir, seguindo delineamento inteiramente casualizado com três repetições, os frutos foram agrupados em subamostras de 100 unidades, a fim de constituir a amostra de trabalho da classificação [6]. Os frutos identificados foram dispostos na bancada, a temperatura ambiente e a classificação foi conduzida de forma a não ultrapassar o período de 12 horas entre a coleta e a análise.

\section{3 - Classificação em grupo, subgrupo, classes e tipo}

A amostra de trabalho foi classificada em grupo, subgrupo, classes e tipo de acordo com a Portaria do MAARA $\mathrm{n}^{\mathrm{o}} 553 / 95$ [6]. Em função do formato, o tomate foi classificado em dois grupos: oblongo e redondo. Oblongo, quando o diâmetro longitudinal foi maior que o transversal e redondo, quando o diâmetro longitudinal foi menor ou igual ao transversal.

De acordo com a coloração e estádio de maturação a amostra foi classificada em cinco subgrupos: verde maduro, pintado, rosado, vermelho e vermelho maduro. Verde maduro: quando se evidenciou o inicio do amarelecimento na região apical do fruto; pintado (de vez): quando as cores amarelo, rosa ou vermelho encontraram-se entre $10 \%$ e $30 \%$ da superficie do fruto; rosado: quando $30 \%$ a $60 \%$ da superficie do fruto encontrou-se vermelha; vermelho: quando o fruto apresentou entre $60 \%$ e $90 \%$ da sua superficie vermelha; vermelho maduro: quando mais de $90 \%$ da superficie do fruto encontravase vermelha.

A classe ou calibre do tomate foi determinada pelo maior diâmetro transversal do fruto em relação ao grupo a que pertence, através de paquímetro de 8 polegadas marca Mitutoyo. O tomate oblongo foi classificado em três classes: grande, médio e pequeno e o tomate redondo foi classificado em quatro classes: gigante, grande, médio e pequeno.

O tipo do tomate de mesa foi definido pela somatória dos defeitos graves e leves presentes nos frutos: podridão, passado, queimado, dano por geada e podridão apical; e defeitos leves: dano, mancha, ocado e imaturo segundo a definição prevista na legislação em vigor [6].

Em razão do tomate orgânico não dispor de legislação que defina a classificação do produto, os frutos foram submetidos à contagem dos defeitos, seguindo a metodologia adotada para o convencional. A amostra de tomate que não atendeu aos requisitos previstos foi classificada como fora do padrão ou fora do tipo [6].

Os resultados foram avaliados pela média e análise de variância (Anova) através do programa Excel em conjunto com todas as amostras, como também comparados separadamente os resultados dos sistemas de cultivo. As médias que apresentaram diferença significativa foram identificadas pelo Teste de Tukey em nivel de 5\% de probabilidade de erro.

\section{3 - RESULTADOS E DISCUSSÃO}

Na classificação, de acordo com o grupo, as amostras do sistema convencional foram redondas e pluriloculares (Figura 1a), confirmando que tomate do grupo salada ou caqui possuem formato redondo, globoso ou achatado e são tipicamente pluriloculares [15]. A exceção, foram as amostras SC1 e SC5 que foram oblongas, pois se tratava de tomate do grupo Santa Cruz, porém trilocular (Figura 1b). As amostras orgânicas foram oblongas, pois todas pertenciam ao grupo Santa Cruz ratificando que cultivares desse grupo apresentam frutos de formato oblongo ou alongado e, predominantemente bilocular (Figura 1c), compativeis com o trabalho de MARTINS \& CASTRO [20], realizado em tomates do grupo Santa Cruz.

Em relação à classe (Figura 2) houve um comportamento semelhante entre as amostras. A classe de frutos médios predominou em relação às demais que se alternaram em percentuais nas diferentes amostras. Esse resultado confirma a preferência dos consumidores de Campinas, que definiram o calibre médio como uma das características de qualidade do tomate de mesa [19]. Na 


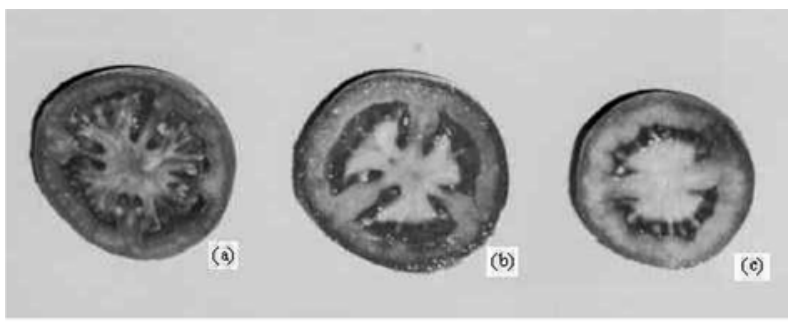

Nota: tomate cultivado no sistema orgânico - bilocular; tomate cultivado no sistema convencional - trilocular e plurilocular.

FIGURA 1 - Número dos lóculos do tomate de mesa cultivado nos sistemas convencional e orgânico comercializado na RMC no período de fevereiro de 2000 a janeiro de 2002

classe pequena, as amostras diferiram entre si tanto grupalmente, como dentro de cada sistema (Figura 2). As amostras SC1, SO1 e SO3, do grupo oblongo, apresentaram o maior percentual de frutos pequenos. No grupo redondo ou salada foram encontrados baixos indices de frutos pequenos, com exceção das amostras SC3 (9,3\%), SC5 $(9,0 \%)$ e SC6 $(14,0 \%)$, que apresentaram um valor superior a $10 \%$ dos frutos pertencentes à classe imediatamente inferior [6, 7], ratificando FLORI [14], que encontrou valores médios de $96 \mathrm{~g}$ de peso em frutos com diâmetro menor que $60,00 \mathrm{~mm}$. Tendo como base essas afirmações e, observando-se os percentuais encontrados no trabalho, pode-se afirmar que no sistema orgânico há uma tendência de apresentar maior percentual de frutos menores em relação ao sistema convencional, fato confirmado na medida massa (dados não disponiveis no trabalho).

A maior concentração de frutos foi encontrada na classe média, confirmando ANDREUCCETTI et al. [4]. Porém, os números encontrados na classe média dos tomates diferiram entre si, tanto no grupo como dentro de cada sistema analisado. As amostras SC4 $(93,3 \%)$ e SO3 $(54,0 \%)$ apresentaram maior e menor valor, respectivamente, para frutos na classe média, conferindo ao tomate orgânico percentuais menores. Se considerar que a importância desta classe está diretamente relacionada com a rentabilidade do produtor, já que os frutos maiores, além de serem melhor remunerados, são os preferidos pelo consumidor [1, 14], o tomate cultivado no sistema orgânico fica em desvantagem comercial.

As amostras analisadas na classe grande apresentaram diferença significativa, tanto no grupo como dentro dos sistemas convencional e orgânico. Somente as amostras SC2, SC5, SO1, SO2 apresentaram percentuais superiores (Figura 2) a classe pequena, compativel com FLORI [14] que encontrou 36\% para cultivares do grupo salada, superior ao maior valor $(23 \%)$ encontrado para a amostra SC5 do grupo redondo. Nas amostras do grupo redondo não foram encontrados frutos da classe gigante, confirmando FLORI [14] que também encontrou baixa proporção de frutos gigantes, o que leva a indagar se esta classe é necessária ao grupo.

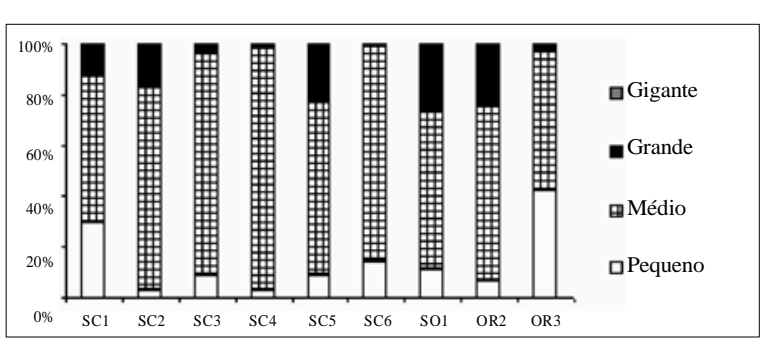

FIGURA 2 - Distribuição percentual das classes do tomate de mesa cultivado nos sistemas convencional e orgânico comercializado na RMC no período de fevereiro de 2000 a janeiro de 2002

A mistura de tomates pertencentes a classes diferentes, permitida pela legislação [6], ultrapassou a somatória dos $10 \%$ dos frutos pertencentes à classe imediatamente superior e/ou inferior. Em caso de classificação mecânica, por calibradores de orificios circulares [27], um número razoável de tomates de menor calibre caem em lotes de outros calibres, sendo indispensável proceder à eliminação manual dos frutos fora de calibre e a sua inclusão nos lotes correspondentes [17]. A exceção foi à amostra SC4 que apresentou 93,3\% de frutos da classe média, conferindo uniformidade de tamanho e peso que são mais fáceis de serem manuseados, pois apresentam menores perdas, produção mais rápida, classificação manual mais fácil e melhor qualidade [11].

Houve a predominância dos subgrupos rosado e vermelho, com exceção das amostras SC2 e SO3 onde os grupos pintado e vermelho maduro, respectivamente foram encontrados com maior freqüência (Figura 3). Na amostra $\mathrm{SC} 1$ foram encontrados $78,6 \%$ de tomates vermelhos e vermelhos maduros. A diferença do estádio de maturação desta amostra em relação às demais, pode ser atribuída à preferência regional $[13,17]$ dos locais de comercialização [25] e emprego culinário [24], enquanto que às demais amostras podem ser levadas a outros locais de comercialização [25], como no varejo onde são revendidas, necessitando de frutos menos maduros. Para mercados próximos, os tomates podem ser colhidos no estádio rosado ou vermelho maduro, enquanto que para mercados distantes podem ser colhidos no estádio de maturação fi-

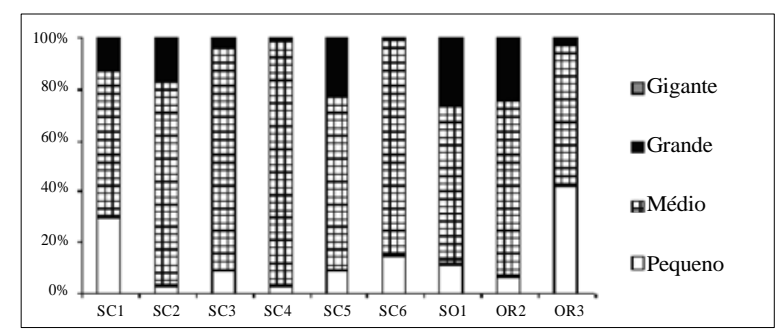

FIGURA 3 - Distribuição percentual dos subgrupos do tomate de mesa cultivado nos sistemas convencional e orgânico comercializado na RMC no período de fevereiro de 2000 a janeiro de 2002 
siológica verde maduro e completar sua maturação fora da planta $[9,17]$, pois o tomate é um fruto climatérico que pode desenvolver cor, aroma e sabor característicos nessa condição. Há mercados, como de Goiânia, que preferem tomate verde maduro e rosado, já no Rio de Janeiro preferem frutos vermelhos ou avermelhados, bem firmes, enquanto que em São Paulo dão preferência a tomates na fase intermediária. Em Campinas os consumidores preferem tomates de mesa na cor rosada (salada) e vermelho (colorido) $[4,13,17,19]$.

Os resultados da coloração do tomate de mesa predominante nas amostras de tomate de mesa encontrados (Figura 3) são compativeis às características técnicas desejadas da cor salada (rosado) e colorido (vermelho) referido por 32 consumidores de Campinas [19]. Donas de casa e aposentados que adquiriram tomate de mesa em um hipermercado da região de Campinas também preferiram frutos de coloração rosada (salada) e vermelha (38\%) e somente tomate vermelho (40\%) [4].

Contrariando as Portarias no 553/95 do MAARA [6] e $\mathrm{SARC} \mathrm{n}^{\mathrm{o}}$ 085/02 [7], que permitem a mistura de até três colorações consecutivas em uma embalagem e no lote, desde que o número de embalagens com a mistura não excedam a 20\%; todas amostras analisadas apresentaram mistura de mais de três subgrupos (colorações) nas embalagens. Esses resultados são compativeis com os resultados aferidos por consumidores [5] que rejeitaram a mistura de padrões, atingindo um percentual de $65,6 \%$ em tomate de mesa comercializados em um supermercado, levando à classificação ruim. A ocorrência de misturas de coloração também foi registrada por ANDREUCCETTI et al. [1] em caixa de tomate cv. Carmen, em 70\% [27] dos atacadistas do CEAGESP.

Quando as amostras analisadas são comparadas às normas da Comissão Econômica Européia [12], Codex Alimentarius [16] e USDA [29], a mistura de estádios de maturação não as comprometem em termos de qualidade, visto que na norma da Comissão Econômica Européia [12] não há definição dos estádios de maturação do tomate e no USDA [29] a classificação não leva em consideração as misturas dos subgrupos.

Quando somados os defeitos encontrados e comparados aos limites por tipo, foi observado que todas as amostras foram classificadas como fora do padrão ou do tipo (Tabela 2), já que os limites de $2 \%, 4 \%$ e $7 \%$ para o total de defeitos graves e $5 \%, 10 \%$ e $15 \%$ [6] para total de frutos com defeitos leves foram ultrapassados para todos tipos: extra, especial ou selecionado e comercial, respectivamente. Os resultados mostraram que o tomate de mesa comercializado na RMC está muito aquém das características desejadas, por exemplo, pelos consumidores de Campinas - SP, que preferem frutos com ausência de defeitos graves [19].

Os defeitos graves que apareceram com maior freqüência foram: podridão, passado e queimado. As amostras analisadas apresentaram um percentual de frutos podres variando de $0,7 \%$ (SC3 e SC4) a 30,0\% (SC6) que leva ao impedimento de beneficiamento e/ou reclassificação das amostras SC2 e SC6 por ultrapassar os 10\% de podridão [6]. Se as amostras SC3 e SC4 fossem comparadas com o limite para o defeito podridão isolado definido pela legislação [6], poderiam ser classificadas na categoria I ou especial. No entanto, na classificação em tipo são somados todos os defeitos das amostras, o que as impede dessa classificação. O maior índice de frutos podres encontrados na amostra SC6 pode ser devido às injúrias causadas pelo transporte e embalagem tipo $\mathrm{K}$, considerada inadequada [10]. No sistema orgânico duas amostras, SO1 (3,0\%) e SO2 (3,3\%), não apresentaram diferença no percentual de frutos podres quando comparadas no grupo, enquanto que a amostra SO3 $(8,3 \%)$ diferiu das demais.

$\mathrm{O}$ defeito passado variou de 0,0\% (SC3 e SC4) a 18,7\% (SO3). As amostras orgânicas SO1 e SO2, que apresentaram os índices baixos de frutos passados, não diferiram estatisticamente entre si ao nivel de $5 \%$ de probabilidade de erro. As amostras SC3, SC4 e SO1, quando comparadas isoladamente aos índices de frutos passados (Tabela 2), foram classificadas como extra. As amostras SC2 e SO2, apesar de não apresentarem diferença estatística com as anteriores, ultrapassaram nos limites da legislação, sendo classificadas como fora de padrão e categoria II ou comercial, respectivamente. A amostra SO3 $(18,7 \%)$ que apresentou o maior valor de frutos passados diferiu da amostra SC1 (15,7\%) e como as demais (SC2, SC5, SC6, SO3) foram classificadas como fora do padrão, já que o tomate de mesa deve ser firme ao tato [28] e quando pressionado não deve se deformar devido ao estádio de maturação [9]. O alto índice de frutos passados na amostra SO3 correlaciona-se ao estádio de maturação da amostra que apresentou $88,0 \%$ de frutos vermelho maduros, que pode ser justificado pela temperatura média $28^{\circ} \mathrm{C} \pm 2^{\circ} \mathrm{C}$, submetida à amostra no dia da colheita. Segundo CASTRO, CORTEZ \& JORGE [10], frutos colhidos no estádio avançado de maturação (maduro) apresentaram riscos de perdas inevitáveis na comercialização face aos golpes, às pressões ou às machucaduras, as quais podem acelerar a respiração, reduzindo a qualidade do fruto.

O defeito queimado foi representado por um alto percentual, variando de $17,0 \%$ a $54,0 \%$ em todas as amostras, exceto a amostra SO3 $(4,0 \%)$, pois se tratava de tomate produzido em estufa. Nas amostras SC5, SC6, SO1 e SO3 foi encontrado menor percentual de frutos queimados em relação às demais amostras, o que pode ser justificado nas primeiras, pois se tratavam de frutos produzidos no inverno, em regiões mais quentes (Tabela 1), quando o sol não era tão intenso.

Dano, por geada, granizo e/ou baixas temperaturas, não foi encontrado em nenhuma das amostras. O defeito por geada, no Brasil, parece ser impróprio, pois o tomate é caracterizado como uma cultura de verão. Na Região Sul é plantado em agosto e a colheita é realizada entre novembro e março, dependendo das condições climáticas. 
TABELA 2 - Classificação em tipos do tomate de mesa cultivado nos sistemas convencional e orgânico comercializados na RMC no período de fevereiro de 2000 a janeiro de 2002

\begin{tabular}{|c|c|c|c|c|c|c|c|}
\hline & DEFEITO (\%) & $\mathrm{SC} 1$ & $\mathrm{SC2}$ & $\mathrm{SC} 3$ & $\mathrm{SC} 4$ & SC5 & SC6 \\
\hline \multirow{5}{*}{ 荧 } & Podridāo & $6,7 \mathrm{acd} A \mathrm{~B}$ & $11,3 \mathrm{cA}$ & $0,7 \mathrm{~dB}$ & $0,7 \mathrm{~dB}$ & $4,0 \mathrm{deB}$ & $30,0 \mathrm{bC}$ \\
\hline & Passado & 15,7 afA & $5,7 \mathrm{bcB}$ & $0,0 \mathrm{bc}$ & $0,0 \mathrm{bC}$ & $9,0 \mathrm{cdeE}$ & $12,0 \mathrm{adD}$ \\
\hline & Queimado & 30,0 abceA & $54,3 \mathrm{acA}$ & 32,3abceA & 35,3abcA & 24,0 cdeA & 23,0beA \\
\hline & Geada & $\mathrm{NE}^{\star \star *}$ & $\mathrm{NE}^{* *}$ & $\mathrm{NE}^{\star \star *}$ & $\mathrm{NE}^{* *}$ & $\mathrm{NE}^{* *}$ & $\mathrm{NE}^{\star \star}$ \\
\hline & Podridão apical & $4,3 a A$ & $2,3 \mathrm{bfB}$ & $1,0 \mathrm{bceBC}$ & $0,0 \mathrm{ceC}$ & $0,0 \mathrm{ceC}$ & $0,0 \mathrm{ceC}$ \\
\hline \multirow{5}{*}{ ఏ్త } & Dano & $46,3 \mathrm{acAC}$ & $72,7 \mathrm{bB}$ & $37,0 \mathrm{adAD}$ & $39,7 \mathrm{Dac}$ & $45,0 \mathrm{acCD}$ & $55,0 \mathrm{cC}$ \\
\hline & Manchado & $13,3 \mathrm{adA}$ & $45,3 \mathrm{bB}$ & $1,0 \mathrm{cA}$ & $2,0 \mathrm{cA}$ & $2,0 \mathrm{cA}$ & $4,0 \mathrm{cdA}$ \\
\hline & Ocado & $0,0 \mathrm{aA}$ & $0,0 a A$ & $0,0 \mathrm{aA}$ & $0,0 \mathrm{aA}$ & $0,0 \mathrm{aA}$ & $0,0 \mathrm{aA}$ \\
\hline & Deformado & 3,7adfAD & 2,0adghAD & 7,7beBC & 1,3ahAD & $0,0 \mathrm{hD}$ & $5,0 \mathrm{deAC}$ \\
\hline & Imaturo & $0,3 a A$ & $7,3 \mathrm{bB}$ & $0,0 \mathrm{aA}$ & $0,0 \mathrm{aA}$ & $0,0 \mathrm{Aa}$ & $0,0 \mathrm{aA}$ \\
\hline Tipo & $\mathrm{FT}^{*}$ & $\mathrm{FT}^{*}$ & $\mathrm{FT}^{*}$ & $\mathrm{FT}^{*}$ & FT* & $\mathrm{FT}^{*}$ & FT* $^{*}$ \\
\hline \multirow{6}{*}{ 总 } & DEFEITO (\%) & \multicolumn{2}{|c|}{ SO1 } & \multicolumn{2}{|c|}{$\mathrm{SO} 2$} & \multicolumn{2}{|c|}{$\mathrm{SO} 3$} \\
\hline & Podridāo & \multicolumn{2}{|c|}{$3,0 \mathrm{deB}$} & \multicolumn{2}{|c|}{ 3,3deBC } & \multicolumn{2}{|c|}{$8,3 \mathrm{deC}$} \\
\hline & Passado & & \multicolumn{2}{|c|}{ 4,ObeFG } & \multicolumn{2}{|c|}{$18,7 \mathrm{eG}$} \\
\hline & Queimado & \multirow{2}{*}{\multicolumn{2}{|c|}{$\begin{array}{c}17,0 \text { bdeB } \\
\mathrm{NE}^{* *}\end{array}$}} & \multicolumn{2}{|c|}{$27,7 \mathrm{cdeC}$} & \multicolumn{2}{|c|}{$4,0 \mathrm{eD}$} \\
\hline & Geada & & & \multicolumn{2}{|c|}{$0,0 \mathrm{aB}$} & \multicolumn{2}{|c|}{$0,0 \mathrm{aB}$} \\
\hline & Podridão apical & \multicolumn{2}{|c|}{$\begin{array}{c}\mathrm{NE}^{* *} \\
11, \mathrm{OdD}\end{array}$} & \multicolumn{2}{|c|}{$1,3 \mathrm{efE}$} & \multicolumn{2}{|c|}{$2,3 \mathrm{bfE}$} \\
\hline \multirow{5}{*}{ 岁 } & Dano & \multicolumn{2}{|c|}{$40,0 \mathrm{adE}$} & \multirow{2}{*}{\multicolumn{2}{|c|}{$\begin{array}{c}\text { 32,3adEF } \\
0,3 \mathrm{cC}\end{array}$}} & \multicolumn{2}{|c|}{$30,7 \mathrm{dF}$} \\
\hline & Manchado & \multicolumn{2}{|c|}{$0,0 \mathrm{cC}$} & & & \multicolumn{2}{|c|}{$0,7 \mathrm{cC}$} \\
\hline & Ocado & \multicolumn{2}{|c|}{$0,0 \mathrm{aB}$} & \multicolumn{2}{|c|}{$0,0 \mathrm{aB}$} & \multicolumn{2}{|c|}{$0,0 \mathrm{aB}$} \\
\hline & Deformado & \multicolumn{2}{|c|}{$0,0 \mathrm{cghE}$} & \multicolumn{2}{|c|}{$0,7 \mathrm{cfghE}$} & & \\
\hline & Imaturo & \multirow{2}{*}{\multicolumn{2}{|c|}{$0,0 \mathrm{aB}$}} & \multicolumn{2}{|c|}{$0,0 \mathrm{aB}$} & & \\
\hline Tipo & $\mathrm{FT}^{*}$ & & & & & & \\
\hline
\end{tabular}

Em estações mais frias, o cultivo pode ser realizado em estufas, ficando protegido de intempéries. A denominação dano por granizo pode ser a nomenclatura mais adequada para esse defeito.

Podridão apical foi um dos defeitos que se apresentaram em pequenas proporções $(0,0 \%$ a $11,0 \%)$ nas amostras analisadas, semelhante ao valor de $8,3 \%$ registrado por CARRIJO et al. [8] em cv. TX e Larissa.

Os defeitos leves que apareceram com maior freqüência foram: dano, manchado e deformado. Dentre esses, o dano foi a injúria que predominou nas amostras de tomate analisadas, em cerca de $44,3 \%$ dos frutos. Quando calculados os sistemas isolados, foi observada uma média de $49,28 \%$ e $34,33 \%$ para o tomate convencional e orgânico, respectivamente.

O percentual de danos nas amostras variou de $72,7 \%$ (SC2) a 30,7\% (SO3), pois a incidência e a severidade da desordem fisiológica dependem da energia de impacto, da cultivar, do número de impactos e do estádio de maturação [22, 23]. Frutos mais maduros perdem a firmeza e se tornam mais susceptiveis a injúrias mecânicas e sensiveis a injúrias internas. As últimas se desenvolvem quando um fruto recebe um impacto sobre o lóculo durante a colheita ou manuseio [22].

As amostras convencionais produzidas em regiões mais próximas apresentaram menores danos quando comparadas com a média do grupo. As exceções foram as amostras SC1 e SC2 que podem ser justificadas pelo local de comercialização, onde os produtores não obedecem critério de seleção e classificação, como também, no caso da amostra SC2, o alto percentual de tomates danificados pode estar relacionado ao ponto de colheita e impacto [10, 22], pois foram frutos colhidos no estádio verde-maduro. Somando os frutos verde-maduro e pintado atingem $42,3 \%$ da amostra.
A amostra SC5 apresentou maior percentual (55,0\%) de danos que a média do sistema convencional (49,28\%), pois são frutos transportados de longas distâncias sob condições favoráveis ao crescimento de microrganismos deteriorantes, principalmente naqueles locais de injúrias mecânicas, como ferimentos por impacto e compressão, cortes e abrasões [4, 22]. Esses resultados são compativeis com os resultados aferidos por consumidores [4] que identificaram $60 \%$ de injúrias em tomates de mesa comercializados em hipermercados. O mesmo ocorreu em tomates de mesa comercializados em um supermercado, onde os consumidores destacaram a presença de injúrias $(68,9 \%)$ nos frutos levando à classificação como ruim [5].

No defeito mancha, as amostras SC3, SC4, SC5, SC6, SO1, SO2 e SO3 não apresentaram diferença ao nível de $5 \%$, variando apenas de $0,0 \%$ a $4,0 \%$. No entanto, as amostras SC1 e SC2, comercializadas pelos produtores, apresentaram $13,3 \%$ e $45,3 \%$ de manchas nos frutos, respectivamente, dados compativeis com as reclamações de consumidores [4], que identificaram 33,3\% de tomates de mesa comercializados em hipermercados com aspecto manchado e de coloração amarelada.

Nas amostras avaliadas não foi encontrado fruto ocado (Tabela 2) isto é, que apresenta vazio entre o tecido da placenta e a polpa, em função do mau desenvolvimento do conteúdo locular $[6,7]$, tornando-se menos suculento, esponjoso e leve [29].

As amostras convencionais, exceto a SC5 do grupo oblongo, apresentaram percentuais maiores de frutos deformados em relação às cultivares orgânicas que apresentaram indices insignificantes. Esses resultados são compativeis com a literatura que indica maior freqüência em tomate redondo [26].

O defeito imaturo foi encontrado (Tabela 2) somente 
nas amostras SC1 (0,3\%) e SC2 (7,3\%), comercializadas pelos produtores, sugerindo que os frutos colhidos não estavam no estádio de maturação ideal ou comercial, ou seja, quando ainda não era visivel o início de amarelecimento na região apical do fruto $[6,7]$.

A somatória dos defeitos encontrados (Tabela 2) classificaram todas as amostras como fora do padrão ou do tipo [6] sugerindo que os produtores não estão preparados para adotá-la, ou então, os padrões quantitativos da legislação são muito rigorosos. Esses resultados confirmam a estatística de que no Brasil há uma perda de hortaliças de $35 \%$ a $40 \%$ na cadeia produtiva, enquanto que em outros países como nos Estados Unidos não passam de $10 \%$ e representam perdas ao nível de produtor, transporte, mercado atacadista e rede varejista [30]. Se fosse considerado como critério os consumidores de Campinas - SP [19], o tomate de mesa deveria apresentar menos de $1 \%$ de defeitos leves, o que leva a deduzir que frutos com muitos defeitos graves não são comercializados e desviados para o descarte, aumentando a perda [30].

Se considerar os defeitos encontrados nos frutos que levou à classificação de todas as amostras como fora do padrão, esse fato se torna mais preocupante em relação ao tomate cultivado no sistema orgânico que apresentou maior percentual de frutos na classe pequena, menor percentual nas classes média e grande e de menor massa (dados não disponiveis). Em se tratando de legislação para tomate de mesa orgânico, no Anexo XVII [7] foi proposto padrão de identidade e qualidade igual ao tomate convencional e não foram consideradas essas diferenças, o que pode levar o tomate cultivado no sistema orgânico a subvalorização comercial. Ou se adota legislação própria para o tomate de mesa orgânico ou se amplia às medidas das classes de maneira a contemplar ambos os sistemas, sem prejuízo das partes.

\section{4 - CONCLUSÕES}

A classificação realizada no tomate de mesa possibilita concluir que as amostras cultivadas no sistema convencional são predominantemente redondas e pluriloculares, a exceção das amostras SC1 e SC5 que são oblongas, do grupo Santa Cruz e triloculares e as do sistema orgânico são do grupo oblongo e biloculares. Na classe, predominaram frutos médios e nas amostras do grupo redondo não estão presentes frutos de tamanho gigante. Há uma predominância do subgrupo rosado e vermelho. A somatória dos defeitos classificam as amostras como fora do padrão ou do tipo.

\section{5 - REFERÊNCIAS BIBLIOGRÁFICAS}

[1] ANDREUCCETTI, C.; FERREIRA, M.D.; GUTIERREZ, S.D.; TAVARES, M. Classificação e padronização de tomate cv. Carmen dentro da CEAGEST (SP). In: 43 CONGRESSO BRASILEIRO DE OLERICULTURA, 2003, Recife. Anais do Congresso Brasileiro de Olericultura, Recife: CBO, 2003a.
[2] ANDREUCCETTI, C.; FERREIRA, M.D.; HONÓRIO, S.L.; GUTIERREZ, S.D.; TAVARES, M. Identificação da forma de trabalho dos atacadistas de tomate de mesa na CEAGESP. In: 43 CONGRESSO BRASILEIRO DE OLERICUlturA, 2003, Recife. Anais do Congresso Brasileiro de Olericultura, Recife: CBO, 2003b.

[3] ANDREUCCETTI, C.; FERREIRA, M.D.; HONÓRIO, S.L.; GUTIERREZ, S.D.; TAVARES, M. Perfil dos atacadistas de tomate quanto à classificação e uso de embalagens na CEAGESP. In: XXXII CONGRESSO BRASILEIRO DE ENGENHARIA AGRÍCOLA, 2003, Goiânia. Anais do XXXII Congresso Brasileiro de Engenharia Agrícola, Goiânia, 2003c.

[4] ANDREUCCETTI, C.; FERREIRA, M.D.; HONÓRIO, S.L.; GUTIERREZ, S.D.; TAVARES, M. Perfil dos consumidores de tomate de mesa em um hipermercado de Campinas - SP. In: XXXII CONGRESSO BRASILEIRO DE ENGENHARIA AGRÍCOLA, 2003, Goiânia. Anais do XXXII Congresso Brasileiro de Engenharia Agrícola, Goiânia, 2003d.

[5] ANDREUCCETTI, C.; FERREIRA, M.D.; TAVARES, M. Reclamações dos consumidores de tomate de mesa em supermercados de Campinas - SP. In: 43 CONGRESSO BRASILEIRO DE OLERICULTURA, 2003, Recife. Anais do Congresso Brasileiro de Olericultura, Recife: CBO, 2003.

[6] BRASIL. Ministério da Agricultura do Abastecimento e da Reforma Agrária. Portaria no 553 de 30 de agosto de 1995 . Dispõe sobre a Norma de Identidade, Qualidade, Acondicionamento e Embalagem do Tomate in natura, para fins de comercialização e Revoga as especificações de Identidade, Qualidade, Acondicionamento e Embalagem do Tomate, estabelecidas pela Portaria no 76 , de 25 de fevereiro de 1975. Diário Oficial da República Federativa do Brasil, Brasília, set. 1995.

[7] BRASIL. Ministério da Agricultura, Pecuária e Abastecimento. Portaria SARC n⿳0 085 de 06 de março de 2002. Propõe o Regulamento técnico de identidade e qualidade para classificação do tomate. Diário Oficial da República Federativa do Brasil, Brasília, mar. 2002. (Consulta pública).

[8] CARRIJO, O.A.; VIDAL, M.C.; REIS, N.V.B.; SOUZA, R B.; MAKISHIMA, N. Produtividade do tomateiro em diferentes substratos e modelos de casas de vegetação. Horticultura Brasileira, Brasília, v. 22, n. 1, p. 05-09, jan./mar. 2004.

[9] CASQUET, E. Principios de economia agraria. Zaragoza: Acribia, 1998.368 p.

[10] CASTRO, L.R.; CORTEZ, L.A.B.; JORGE, J.T. Influência da embalagem no desenvolvimento de injúrias mecânicas em tomates. Ciênc. Tecnol. Aliment., Campinas, v. 21, n. 1, p. 26-33, jan./abr. 2001.

[11] ChitarRa, M.I.; CHITARRA, A.B. Pós-colheita de frutos e hortaliças: fisiologia e manuseio. Lavras: ESAL/FAEPE, 1990.320 p.

[12] ECE - ECONOMIC COMMISSION FOR EUROPE. $\mathrm{UN} / \mathrm{ECE}$ standard ffv-36. Concerning the marketing and commercial quality control or tomatoes moving in international trade and to UN/ECE member countries. Committee for trade, industry and enterprise 
development. Genebra: 2000. (report or the fitfy-sixth session, nov). p. 27-30.

[13] FILGUEIRA, F.A.R. Novo Manual de Olericultura: agrotecnologia moderna na produção e comercialização de hortaliças. 2. ed: Viçosa: UFV, 2003, 412 p.

[14] FLORI, J.E. Obtenção e avaliação de híbridos F, de tomate (Licopersicon esculentum Mill) no grupo multilocular. 1993. 144 f. Dissertação (Mestrado em Agronomia, área de concentração Fitotecnia) - Escola Superior de Agricultura de Lavras.

[15] FONTES, P.C.R.; SILVA, D.J.H. Produção de tomate de mesa. Viçosa: Aprenda Fácil, 2002. 197p.

[16] FAO - FOOD AND AGRICULTURE ORGANIZATION OF THE UNITED NATIONS. Codex Alimentarius commission. Proposed draft codex standard for tomatoes. Joint FAO/OMS food standards programme. Disponivel em:

<http://www.codexalimentarius.net/c10/ff0 201e.htm> Acesso em: 24 abr. 2002. 3 p.

[17] GAYET, J.P.; BLEINROTH, E.W.; MATALLO, M.; GARCIA, E.E.C.; GARCIA, A.E.; ARDITO, E.F.G.; BORDIN, M.R. Tomate para Exportação: Procedimentos de Colheita e Pós-colheita. Ministério da Agricultura, do Abastecimento e da Reforma Agrária, Secretaria do Desenvolvimento Rural, Programa de Apoio à Produção e Exportação de Frutas, Hortaliças, Flores e Plantas Ornamentais - Brasília: EMBRAPA-SPI, 1995. 34p. Série Publicações Técnicas FRUPEX; 13).

[18] GERÊNCIA DE CLASSIFICAÇÃO. Classificação de produtos de origem vegetal. Disponivel em: <http://www.sc.gov.br> Acesso em: 12 out. 2001.

[19] MARCOS, S.K.; JORGE, J.T. Desenvolvimento de tomate de mesa, com uso do método QFD (Desdobramento da Função Qualidade), comercializado em um supermercado. Horticultura brasileira, Brasília, 20. n. 3. 2002.

[20] MARTins, M.B.G.; CASTRO, P.R.C. Aspectos morfoanatômicos de frutos de tomateiro cultivar Ângela Gigante, submetidos a tratamento com reguladores vegetais. Bragantia, Campinas, v. 56, n. 2, p. 225-236, 1997a.

[21] MORAIS, F. Aumenta a adesão de agricultores para classificação de produtos. Leste on line. Disponível em: <http://lesteonline.intermol.com.br/agricultura> Acesso em: 13 de outubro de 2001.
[22] MORETTI, C.L.; SARGENT, S.A. Alteração de sabor e aroma em tomates causada por impacto. Scientia Agricola, Piracicaba, v. 57 , n. 3 , p. $385-388$, jul./set. 2000.

[23] MORETTI, C.L.; SARGENT, S.A.; HUBER, D.J.; PUSCHMANN, R. Armazenamento sob atmosfera controlada de tomates com injúrias internas de impacto. Horticultura Brasileira, Brasília, v. 20, n. 3, p. 465-469, set. 2002.

[24] PAZINATO, B.C.; GALHARDO, R.C. Processamento artesanal do tomate. 2 impressão. Campinas: Coordenadoria de Assistência Técnica Integral, 1997. $30 \mathrm{p}$.

[25] SEAGRI - SECRETARIA DE AGRICULTURA, IRRIGAÇÃO E REFORMA AGRÁRIA. EMBRAPA. Cultura-tomate. BAHIA. Disponível em:

<http://www.bahia.ba.gov.br/seagri/tomate.htm> Acesso em: 8 mai. 2002.

[26] SILVA, J.B.C.; GIORDANO, L.B. Tomate para processamento industrial. Brasília: Embrapa Comunicação para Transferência de Tecnologia Embrapa Hortaliças, 2000, 168 p.

[27] SILVA, G. Seleção apurada. Revista Globo Rural, Jaguaré, v. 16, n. 191 p. 59-61, set. 2001.

[28] SUSLOW, T.V.; CANTWELL, M. Tomate: (Jitomate). Recomendaciones para Mantener la Calidad Postcosecha. Davis: Department of Vegetable Crops, University of California. 2003. 5p.

[29] USDA - UNITED STATES DEPARTAMENT OF AGRICULTURE. Fruit and vegetable division. United States standards for grades of fresh tomatoes. Reprinted january 1997. Disponivel em: <http://www.ams.usda.gov/standerds.tomatfrh.pdf> Acesso em: 29 abr. 2002.

[30] VILELA, J.N.; LANA, M.M.; NASCIMENTO, E.F.; MAKISHIMA, N. O peso da perda de alimentos para a sociedade: o caso de hortaliças. Horticultura Brasileira, Brasília, v. 21, n. 2, p. 141-143, abr./jun. 2003.

\section{6 - AGRADECIMENTOS}

Ao Programa PIBIC/UFPR pela concessão de bolsa, Associação d'Agricultura Orgânica do Paraná AOPA, Produtores Agrícolas de Colombo - APAC e BIG Hipermercados (Loja Torres) que cederam amostras. 